\title{
Views of teachers' and Interns' regarding teaching- learning of communication skills in undergraduate medical education in Bangladesh
}

\author{
Dr. Abu Saleh Mohammed Monirul Alam ${ }^{1}$, Dr. Md. Humayun Kabir Talukder ${ }^{2}$, Dr. Farhana Haque ${ }^{3}$, \\ Dr. Shah Mohammed Hafizur Rahman ${ }^{4}$, Dr. Md. Shoheilul Amin ${ }^{5}$, Dr. Jamil Ahsan Ansary ${ }^{6}$.
}

\begin{abstract}
This cross-sectional descriptive study was carried out among the teachers and interns doctors of four medical colleges of Dhaka city in last one year (2010-2011).Data was collected by conveniance sampling.

In-depth interview of the teachers were taken to explore their views regarding current situation, what should be, and recommendations for future curriculum about teaching communication skills. Information was collected from interns by semi-structured questionnarie. Alocation of score for response of each item was based on 5 point Likert scale.Total respondents were 249 out of which intern doctors were 218 and 31 were teachers. Teachers were chosen from eight clinical subjects as the conveniance of the researcher. Selected 14 variables of communication skills were used in this study.

By reviewing the study it was seen that most of the interns gave opinion that they were not taught communication skills in their cinical classes. It was seen in the study that majority of the teachers confessed that they don't teach communication skills in stuctured way. All of them agreed that it must be taught in stuctured way and assessed.
\end{abstract}

\section{Introduction}

Increasing number of medical schools have included brief training course in communication skills. While there is evidence that such course do improve student's skill' ${ }^{1}$. It has become increasingly clear that how doctor communicates with the patient $\mathrm{s}$ affect the accuracy of diagnosis, compliance, satisfaction and response to investigation and treatment. ${ }^{2}$ Trained doctors are more able to communicate warmth and understanding to patients ${ }^{3,4}$ and are more able for detecting and responding appropriately to patient's verbal and non verbal cues ${ }^{5,4}$. To produce graduates with a range of communication skills and attributes Liverpool university introduce communication skill learning course throughout five years ${ }^{6}$. The four year program in University of Maastricht, which has started four year programs of communication skills training?

In our under graduate curriculum there are four week period

${ }^{1}$ Asst. Professor, Ortho surgery, deputed in CME, Dhaka.

${ }^{2}$ Professor, Curriculum Development \& Evaluation, Center for Medical Education (CME), Dhaka.

${ }^{3}$ Senior Medical Officer, INM \& Ultrasound, BSMMU campus, Dhaka.

${ }^{4}$ Asst. Professor, Ortho surgery, CME, Dhaka.

${ }^{5}$ Lecturer, Pioneer Dental College, Dhaka.

${ }^{6}$ Lecturer, Pioneer Dental College, Dhaka.

Address of correspondence: Dr. A S M Monirul Alam E-mail: asmmalam@yahoo.com Tel.01711979926 of communication learning skill in community medicine ${ }^{8}$. In informal way there are are scope of learning communication skill in clinical classes by 'History taking", by observing senior's communication with the patient.

\section{Methodology}

This cross-sectional descriptive study was carried out among the teacers and interns doctors of four medical colleges of Dhaka city in last one year (2010-2011). Data were collected by conveniance sampling. Two public medical colleges and two private medical colleges were chosen according to the convenience of the researcher.

In-depth interview of the 31 teachers of eight clinical subjects of four medical colleges were taken to explore their views regarding current situation, what should be, and recommendations for future curriculum about teaching communication skill. Information was collected from 218 interns by self administered semi-structured questionnaires contain 26 questions from the variables. Alocation of score for response of each item was based on 5 point Likert scale. All the answers were recorded by writing and checked at the end of the interview. All the instuments were developed and finalized after pretesting. The instruments were pre-tested at Chittagong medical college.

\section{Result}

The result of the answer of questionnaires by interns' analysed by using SPSS soft wear package and was as follows. Out of 218 respondents $177(81.2 \%)$ agreed that teacher taught them how to build Rapport, 206 (94.4\%) 
agreed that teacher taught them how to take informed consent, $92(42.2 \%)$ some how undecided and disagreed that teacher taught them how to convince patient and guardian to do a painful procedure, $165(75.7 \%)$ agreed that teacher taught them how to counseling the patient about life style and diet.

\begin{tabular}{|l|c|c|}
\hline Name of the Institute & Frequency & Percent \\
\hline Dhaka National Medical College & 53 & 24.3 \\
\hline Dhaka Medical College & 63 & 28.9 \\
\hline Sir Salimullah Medical College & 71 & 32.6 \\
\hline $\begin{array}{l}\text { Holy Family Red Crescent } \\
\text { Medical College }\end{array}$ & 31 & 14.2 \\
\hline Total & 218 & 100.0 \\
\hline
\end{tabular}

Table 1: Distribution of respondent interns as per their institutions 90 (41.3\%) interns some how undecided and disagreed that teacher taught them how to break the bad news to the patient and the guardian, $91(41.8 \%)$ some how undecided and disagreed that teacher taught them how a difficult situation can be managed, 173 (79.4\%) agreed that teacher should taught them how they will convince and refer the patient to another hospital.

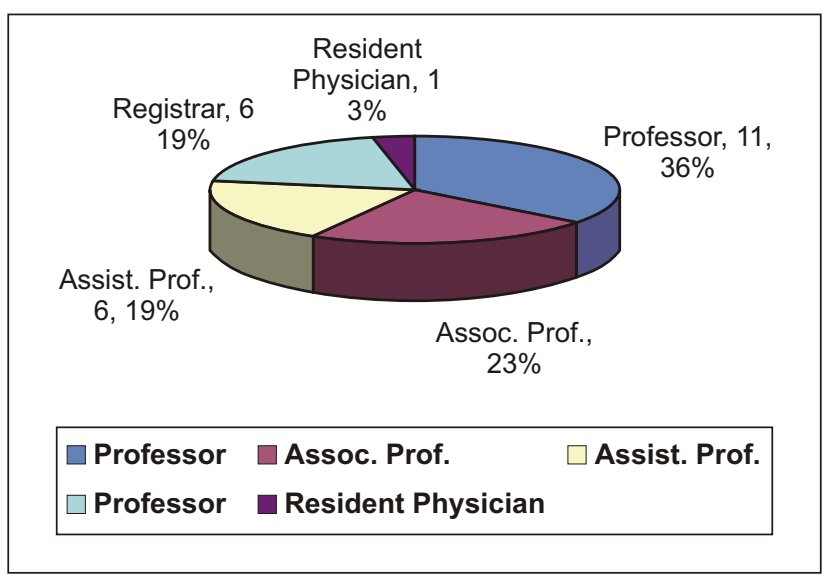

Chart: 1 Distribution of respondent teachers by designation

Most of the teachers (24) taught students how to take informed consent, it's importance and it's legal aspect. A large group of teacher (21) said that student should learn how to motivate the hesitating patient to receive treatment and practiced it in internship period. As they will be then involved in the treatment procedure of the patient, so they can explain about the danger of not receiving treatment.

About half of the respondent teachers answered that they teach students about how to motivate the patient for a painful procedure in clinical class. Some of them added that they teach it in infrequently but gave emphasis that it should be taught in structured way. training. About one third of the respondent teacher told that they have taught students how to break the bad news in the clinical class. Few teachers told that they have taught the students only when related patient was available in the ward. They gave emphasis for using simulator so all students have opportunity to learn. About one third of the respondent teachers (9) answered that they have taught students how to handle difficult situation only when any occurance happened in the ward/hospital. They opined that it should be learnt in internship training. Because in this period trainee doctors get enough time to learn this from surroundings and seniors. Majority of the respondent teachers (16) gave opinion that they donot teach students regarding patient's referral.

Majority of the respondent teachers admitted that they donot teach students about how to break the bad news, how to handle difficult situation, how to counselling the patient and their guardian about patient's life style and diet and other variables of communication skills rather they told that they thought the students should learn it better in internship training. Few teachers opined that they should learn it in the class in structured way.

Regarding the opinion of the teachers about teaching communication skill in the clinical class and what will be the topics/content, following opinions were obtained. A large group of respondent teachers answered that variables described in this study are almost sufficient and few topics can be added. They suggested that all this can be included in a clinical subject like medicine or pschychiatry, as a chapter. Teaching can be given in various ways such as lecture, tutorial, small group discussion in ward etc. For ensuring the learning they recommended that assesment must be taken.

\section{Discussion}

Indepth interview with the teachers of clinical subjects of four medical colleges were taken to explore their views regarding current status about teaching communication skills. Selected 14 variables of communication skills were used in this study. Similar variables used by others in their studies. ${ }^{9,10,11}$

$89.9 \%$ interns answered that they should taught how to build rapport of the patient to the student where as $81.2 \%$ answered that teachers taught them. So there was disparity between expectation and happening. In interviews all the teachers agreed that it must be taught in clinical class in structured way. Aspergen discussed in their published article that rapport building clearly need to be taught and trained in medical school and post graduate courses ${ }^{9}$.In interview majority teachers (24) told that they teach students how to take inform consent, and it's legal aspect.as students' also agreed. A study have shown that the difference between pretest and post test score regarding this variable was higly significant ${ }^{10}$.

A good number (42.2\%) of interns denied that they were taught how to convince patient and their guardian for

Bangladesh Journal of Medical Education 2012;2(1):14-17. 
accepting a painful procedure as a treatment. But three fourth $(75.7 \%)$ of them answered that they should taught it in their student life. But remarkable

difference was seen in teachers' view. More than half $(54.8 \%)$ of the teacher didn't teach it the student as they thought that it should be learnt in internship.

Most of the interns agreed (75.7\%) that they were taught how to counseling the patient about diet and life style after discharge from hospital and $80.8 \%$ of them thought that it must be taught. In interview most of the respondent teachers $(58 \%)$ admitted that they did not teach it.. Difference in the opinion possibly due to misunderstand and in-correct answer of the students. They were taught in community medicine class and they forgot it during giving answer. Other possibility was that, they learn it in ward round where assistant register and intern write this in the discharge letter.

More than half $(57.8 \%)$ of the interns admitted that they were taught how to break bad news to the patient. In interview only one third of teachers told that they taught it. Similarl findings came through the result of study done by others. ${ }^{10}$ Rosenbaum stated in their review article that majority of the clinicians have not received formal training in this essential and important communication task ${ }^{12}$.

More than half (58.3\%) of the interns agreed that they were taught how a difficult situation can be managed.. Majority of respondents intern $(79.3 \%)$ answered that they were taught how to convince and refer the patient to another hospital for better management. Majority of the respondent teachers gave opinion that they didnot teach students structurally. The difference between the teachers and the interns are interestingand the cause described above.In this study it was seen that most of the variables regarding communication skills were taught in unstructured way. But according to interns' view it should be taught more and in a stuctured way in the curriculum. This finding has a similarity with another study ${ }^{13}$. They have shown in their study that $67 \%$ junior house officer felt that they had learnt adequate communication skills in relation to medicine.

\section{Conclusion}

Reviewing the findings of the study, it can be concluded that communication skills are must know skill for the doctors. Most of the interns gave answer that they were not taught majority of the communication skills mention in this study in their MBBS course. But in internship period they were feeling that those should be taught in structured way. Some of the interns recommended that communication skills should taught as a part of curriculum so every student have equal opportuniyy of leaning these skills.

From the indepth interviews of teachers multiple opinion were obtained regarding teaching communication skills in undergraduate medical education. All of the teachers agreed that it must be taught either in clinical classes or during internship period.
From this study following recommendations can be made.

1. Communication skills teaching should include in the curriculum of MBBS course. It may be included as a chapter in any existing subject such as Medicine.

2. It should be taught in the clinical class. Few lecture class can be set to give ideas about the introduction, importance, relevance and advantages of learning communication skills.

3. There should have scope of assessment of students about the acquiring and learning of communication skills by OSCE or other method.

4. A curriculum should be set for the interns, which will include communication skills.

\section{References}

1. Maguire P, Fairbairn S, and Fletcher, C (1986). Consultation skill of Young Doctors:I Benefits of feedback training in interviewing as students persist. British medical journal. 292: 1573-1576. Sanson Fisher

2. Sanson-Fisher R W, and Maguire P (1980). Should Skill in Communicating with patients be taught in medical school? The Lancet, ii: 523-6.

3. Engler C M, Saltzman G.A.,Walker M.L, Wolf F M (1981). Medical students acquisition and retention of communication and interviewing skills, Journal of medical education, 56: 572-9

4. Alroy G, Ber R., Kramer D, (1984). An evaluation of short term effects of an skills course. Medical education 18: 85-9.

5. Pool A D, Sanson- Fisher R W (1979). Understanding the patient ; a neglected aspect of the medical education. Social science and medicine. 13:37-43.

6. Watmough S, Garden A, and Taylor D (2006). Does a new integrated PBL curriculum with specific communication skills classes produce Preregistration house officers (PRHO) with improved communication skills. Medical Teachers, 28 (3): 264-269.

7. Dalen J V, Hout J C H M V, Wolfhagen $\mathrm{H} \mathrm{A} \mathrm{P,}$ Scherpbier A J J A, Vleuten C P M V (1999). Factors influencing effectiveness of communication skill. Medical Teacher, 21(2): 308-310.

8. Curriculum for undergraduate Medical Education in Bangladesh. Approved by Bangladesh Medical \& Dental council. Edited by Centre for Medical Education.2002.

9. Aspergen K, Knut \& Madesan P L(2005. Which basic knowledge are learnt spontaneously and which need to be taught? Medical Teachers, 27(6): 539-543 
10. Faiz, M.A. et al , (2007). Effect of training of communication skill on Doctors. Journal of Dhaka Medical College, 16(2): 55-59.

11. Hargie O, Mairead B, Kim H (1998). A survey of communication skill's training in UK school of medicine. Medical Education, 32:25-34.
12. Rosenbaum M E, Ferguson K J, Lobas J G (2004). Teaching Medical Students and Residents Skills for Delivering Bad News: A Review of Strategies. Academic Medicine. 79 (2): 107-117.

13. Cantall B M, Ramirez A F (1997). Doctor patient communication; A study of junior house officers. Medical education, 31: 17-21 